\title{
ESPECIFICAÇÃO DE UM PROJETO PARA DESENVOLVIMENTO DE OBJETOS DE APRENDIZAGEM INTERATIVO
}

\author{
SPECIFICATION OF A PROJECT FOR THE DEVELOPMENT OF INTER- \\ ACTIVE LEARNING OBJECTS
}

José Torres, Angelita Mendes e

Márcio Souza

O multifacetado processo de ensino e aprendizagem ganha novos contornos e amplia seu alcance em função de forte investimento na criação, adaptação e disseminação de tecnologias para a educação. As especificidades desse processo, todavia, exigem meticuloso planejamento e acurado desenvolvimento já que a utilização de materiais didáticos convencionais/tradicionais mostraram-se inadequados. Logo, a elaboração de Objetos de Aprendizagem demanda sistematização de seu processo de desenvolvimento como forma de ampliar a probabilidade de sucesso. As metodologias propõem um procedimento, normalmente, baseado no processo de desenvolvimento de software, mas, às vezes, minoram no levantamento das especificações pedagógicas e tecnológicas desses objetos de aprendizagem. Este trabalho, assim, propõe um Processo de Desenvolvimento de Objeto de Aprendizagem Interativo - PDOAI -, de modo a adequar o desenvolvimento dos Objetos de aprendizagem às estratégias da instituição, atendendo às necessidades pedagógicas e técnicas. Esse processo, então, foi desenvolvido para uma unidade da disciplina de Engenharia, para a qual se mostrou adequada.

Palavras chave: objeto de aprendizagem, metodologia, ambiente virtual de aprendizagem.

The multi-faceted process of teaching and learning acquires new contours and expands its outreach in terms of investment in the creation, adaptation, and dissemination of technologies for education. The specificities of the process, however, require meticulous planning and thorough development, since the use of conventional/ traditional teaching material proved inadequate. Therefore, the drafting of Learning Objects demands systematization of its development process as a way to increase the probability of success. The methodologies propose a procedure normally based on the software's development, but sometimes it diminishes the collection of relevance of the pedagogical and technological specifications for those learning objects. The present study thus proposes an Interactive Development Process of Learning Object - PDOAI, in Portuguese - so that the development of the Learning Objects suits the institution's strategies, by meeting the teaching and technical needs. This process was then applied to an Engineering discipline unit, for which it proved suitable.

Keywords: learning objects, methodology, virtual learning environment. 


\section{Introdução}

Resultados nada promissores sobre a educação no mundo, seja no que tange à universalização, à qualidade do ensino e da aprendizagem ou ao atendimento aos diferentes estilos de aprender contidos em cada estudante impulsionam o investimento para criação, adaptação e disseminação de tecnologias, fortalecendo a Educação a distância e os conteúdos abertos como forma para atingir mais e mais jovens e adultos. Renomadas universidades de todo o mundo rendem-se ao alcance de milhares de pessoas ao redor do mundo em função do acesso que a internet proporciona. Dai que pensar materiais apropriados tornam-se uma enorme necessidade, pois não cabe mais a mera disponibilização de materiais tradicionais nos Ambientes Virtuais de Ensino e Aprendizagem - AVEA. Nesse sentido, a condição sine qua non é a qualidade dos conteúdos dispostos nesses espaços, tematizando a uma necessidade imediata de elaboração de adequados Objetos de Aprendizagem.

Para Braga (2014), Objetos de Aprendizagem são unidades digitais, catalogados e disponibilizados em repositórios na Internet para serem utilizados no ensino e na aprendizagem. Esses são constituídos a partir de diversos recursos como vídeo, jogos e textos, por exemplo, nominados individualmente de componentes ou elementos constituintes. O Instituto de Engenharia Elétrica e Eletrônica - IEEE -, definiu Objetos de Aprendizagem como qualquer entidade, digital ou não, que pode ser usada, reutilizada ou referenciada durante o aprendizado apoiado pela tecnologia; todavia, Abarca (2014) defende que atualmente um Objeto de Aprendizagem inclui mais elementos gráficos em detrimento da redução de conteúdos textuais extensos, tornando-o mais atrativo.

A variedade de recursos, isto é, de elementos constituintes, na elaboração de Objeto de aprendizagem $\mathrm{OA}$ - associado à multiplicidade de objetivos educacionais comprometidos em atender as necessidades de aprendizagem individuais dos estudantes tornam o desenvolvimento de OA uma atividade complexa e contam com inúmeras possibilidades de desenvolvimento, o que demanda um planejamento criterioso por meio de um projeto.

O guia PMBOK (2008) define projeto como um empreendimento temporário com o objetivo de entregar um produto ou serviço único com começo e fim bem definido. Para esse guia, um projeto deve ser constituído de um ciclo de vida e esse deve ser constituído de fases ou etapas e atividades, portanto, um processo de desenvolvimento como base para a elaboração de um projeto. Assim, o desenvolvimento de um Objeto de Aprendizagem deve ser considerado um projeto e deve ter como base um modelo de referência baseado em processo para o seu desenvolvimento.

Desse modo, para o desenvolvimento de Objetos de Aprendizagem é fundamental a utilização de um processo que sirva como modelo. O Processo de Desenvolvimento de Produto - PDP, segundo Rozenfeld et al. (2006), é um conjunto de atividades capaz de transformar informações tecnológicas e de mercado em produtos/serviços de acordo com as estratégias da empresa, atendendo às necessidades da produção, acompanhamento e retirada de um produto do mercado. Busca, portanto, a especificação do projeto do produto. Como se verá mais adiante, a proposição objeto deste estudo para o desenvolvimento de OA aproxima-se da definição do PDP.

Mesmo com o modelo de referência, o desenvolvimento de um Objeto de Aprendizagem - OA - é complexo, principalmente em função do seu reuso. As principais características de um OA são a sua granularidade e a sua agregação, segundo Braga (2014). De maneira geral, a palavra granularidade origina-se da palavra grão, sendo que quanto maior o número de grãos de um sistema maior a sua granularidade. Trazendo esse conceito para o âmbito do OA, a granularidade é a extensão formada por componentes ou elementos constituintes menores e reutilizáveis. Assim, um OA é composto de diversos outros OA menores. Para a referida autora, agregação significa a capacidade de seus grãos serem agrupados em conjuntos maiores de conteúdo; assim, um OA pode ter um número alto de grãos, porém com baixa agregação. Ela justifica essa afirmação por meio de um exemplo de um curso a distância em que cada aula é um grão. Segundo ela, esse curso pode ter uma quantidade alta de grãos, mas, com uma baixa agregação, pois existe uma dependência conceitual entre os grãos, dificultando o reuso do OA. Segundo a autora, um vídeo de 10 minutos tem uma baixa granularidade, mas, pode-se aumentar a granularidade desse OA editando esse vídeo e dividindo em 5 vídeos de 2 minutos. Assim, cada vídeo poderia ser apresentado em uma aula diferente e até mesmo em disciplinas diferentes. 
Concebe-se neste estudo que um Objeto de Aprendizagem deve permitir a integração teoria/prática de forma autônoma e associada aos Ambientes Virtuais de Ensino e de Aprendizagem - AVEA - possa ser trabalhado para permitir colaboração no processo educacional. Como uma característica importante, pode-se citar a flexibilidade no sentido de poder incorporar novos componentes ao OA. Esses componentes podem ser de diversos tipos como um novo problema, uma nova mídia ou um novo texto. Uma outra característica importante é a navegação sobre os seus elementos constituintes. Desse modo, o software de navegação deve permitir o acesso aos seus elementos da forma que o aluno achar melhor, atendendo suas necessidades de aprendizagem, permitindo acessos paralelos e sequenciais a seus elementos constituintes, ou seja, um elemento só pode ser acessado se um outro já tiver sido acessado e devidamente dominado, por exemplo.

Em função dos aspectos levantados anteriormente, este estudo propõe um modelo de Processo de Desenvolvimento de OA Interativo - PDOAI - aqui entendido como conjunto de atividades capaz de transformar informações tecnológicas e pedagógicas em Objetos de Aprendizagem, tendo como objetivo adequar esse processo de desenvolvimento às estratégias da instituição, atendendo às necessidades da sua estrutura de desenvolvimento. Este trabalho está organizado da seguinte forma: na seção 2 é apresentado o levantamento de algumas das metodologias de desenvolvimento de OA. O modelo de processo é apresentado na seção 3 e na seção 4 apresenta-se o desenvolvimento do modelo proposto para uma disciplina, enquanto a

seção 5 traz as considerações finais do estudo.

\section{Levantamento de Metodologias de Elaboração de Objetos de Aprendiza- gem}

A concepção e desenvolvimento de um Objeto de Aprendizagem, como também a sua escolha e utilização, deve levar em conta os fatores que determinam uma maior ou menor interatividade, e identifica que um deles é a concepção epistemológica e de aprendizagem, segundo Braga (2014). Para a autora, a título de exemplificação, se determinado conhecimento deve ser desenvolvido nos alunos, predominantemente, por meio de memorização, certamente, se buscará por Objetos de Aprendizagem que apresentem essas informações a serem memorizadas e/ou que apresentarão perguntas para respostas diretas e objetivas, sem exigir muita reflexão. Braga (2014) apresenta como exemplos de casos de memorização: alunos de medicina que necessitam saber o nome de todos os ossos do corpo humano; crianças que precisam aprender a tabuada, e afirma ainda que um Objeto de Aprendizagem pouco interativo, por si só, pode constituir um recurso interessante em uma aula interativa.

Por outro lado, ela afirma que se a concepção for possibilitar o aprendizado do aluno por meio de situações problemas, de forma a colocar em jogo o conhecimento que já possui, ao buscar novas informações e desempenhar papel ativo, deve-se pensar nos Objetos de Aprendizagem que, de alguma maneira, promovam a reflexão no aluno por meio de desafios e problemas a resolver.
Logo, são inúmeras as possibilidades de utilização desses elementos na educação em função de vasta combinação de elementos que poderão atender ao desenvolvimento de inúmeros processos de aprendizagem, o que demanda, todavia, atenção redobrada no processo de elaboração desses Objetos de Aprendizagem. Para tanto, o processo de desenvolvimento utiliza diversas ferramentas como mapa conceitual, roteiros, storyboard e mapa de navegação. Interessa em especial a utilização de mapas conceituais, neste estudo, tomando como referencia a definição de Novak (apud OKADA, 2016) como uma representação de conceitos e suas relações mediante ligações hierárquicas descritas por palavras que estabelecem relações ou proposições válidas para compreensão de significados dentro de certo domínio de conhecimento.

Kemczinski (2012) afirma que os Objetos de Aprendizagem devem atender a maioria das características técnicas e pedagógicas que compreendem o processo educacional. No que respeita à perspectiva pedagógica dos Objetos de Aprendizagem, a autora destaca a importância desses elementos apresentarem interatividade, estimularem autonomia e cooperação, favorecerem a cognição e o afeto, sem, no entanto descurar da articulação com as características técnicas de adaptabilidade, de agregação e classificação, do aspecto digital, da durabilidade, interoperabilidade e reusabilidade.

\section{Diretrizes para desenvolvimento de Objetos de Aprendizagem}


Neste trabalho, foram levantadas várias metodologias de Desenvolvimento de Objetos de Aprendizagem - OA - ou Design Instrucional - DI. Duas metodologias clássicas de DI como ADDIE - Analysis, Design, Development, Implementation e evaluation e RIVED foram citadas indiretamente por outras metodologias apresentadas aqui. Em função dos Objetos de Aprendizagem - OA - serem considerados objetos digitais, Kemczinski (2012) pondera que um OA é considerado como um produto de software, resultante do processo final da aplicação de uma metodologia, ou seja, o DI é definido como processo (conjunto de atividades) para identificar um problema (uma necessidade) de aprendizagem e desenhar, implementar e avaliar uma solução para esse problema. Porém, não é função da metodologia descrever todas as técnicas a serem utilizadas no processo de desenvolvimento de um OA, como vídeos ou jogos. Para o desenvolvimento desses objetos, serão utilizadas metodologias específicas e as técnicas utilizadas estão nos conhecimentos de cada área específica. Para cada fase da metodologia, são gerados artefatos que são avaliados em relação às características pedagógicas e técnicas.

Kemczinski (2012) propôs uma metodologia à qual chamou de Metodologia de Construção de Objetos de Aprendizagem Interativa - MCOAI. Segundo a autora, a metodologia é baseada na tradicional área de engenharia de software, porém contando com a interatividade do processo de aprendizagem que consiste em dois pontos principais: (i) a definição das equipes pedagógicas e técnicas; e (ii) a especificação e desenvolvimento do Objeto de Aprendizagem. De acordo com essa metodologia, equipe técnica deverá ser composta por profissionais com uma base de conhecimento em programação e com domínio de ferramentas de desenvolvimento que permitam a interatividade dos Objetos de Aprendizagem, tais como Synfig Studio, Adobe Flash, Java, entre outras. Já a equipe pedagógica deverá ser composta por profissionais de domínio da área de conhecimento abordada pelo Objeto de Aprendizagem, no caso caracterizados como professores conteudistas. A equipe técnica é responsável pela etapa de implementação, ou seja, em desenvolver os Objetos de Aprendizagem com base na especificação gerada pela equipe pedagógica.

Essa metodologia é baseada em seis (6) etapas: (i) Análise, (ii) Projeto, (iii) Implementação, (iv) Submissão, (v) Avaliação e (vi) Publicação. Os professores conteudistas da área do Objeto de Aprendizagem a ser desenvolvido são responsáveis pelas etapas de Análise e Projeto. A essa equipe, é atribuída a responsabilidade pela construção do mapa conceitual, dos roteiros e do mapa navegacional e, principalmente, pela construção da Matriz de Design Instrucional - MDI. Essa matriz é composta de atributos como unidade de aprendizagem, objetivos, papéis e definição de atividades responsáveis pelo alcance dos objetivos, duração da aprendizagem e ferramentas e conteúdo de apoio e por último a forma de avaliação desses Objetos de Aprendizagem.

Costa (2014) propõe uma estrutura para especificação dos objetivos da Matriz de Design Instrucional - MDI - da unidade de aprendizagem relacionada com o processo proposto por Fillatro (apud COSTA, 2014) e pela taxonomia de Bloom. Para cada objetivo especificado, existem quatro atividades, a saber, Introdução, Processo, Conclusão e Avaliação. Além disso, um conjunto de eventos instrucionais são propostos e utilizados para a especificação das atividades. Ele apresenta um exemplo para o preenchimento das atividades na MDI, assim, caso

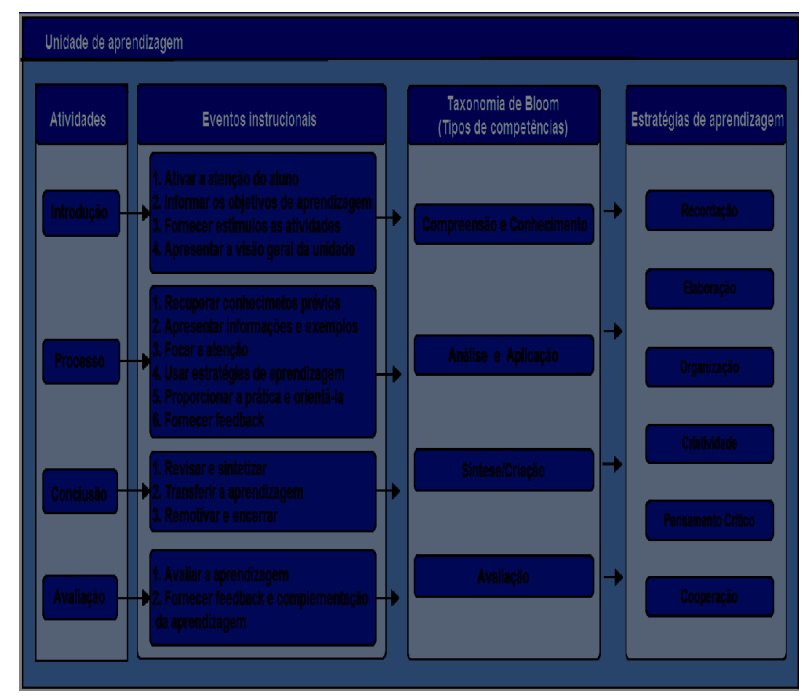

Figura 1: Estrutura de especificação de atividades. Fonte: Elaborado por Fillatro (apud COSTA, 2014) 
a atividade esteja relacionada à fase de Introdução, o primeiro evento instrucional a ser explanado é ativar a atenção do aluno. A figura 1 apresenta a estrutura de especificação das atividades.

Em Torres et al. (2016) encontra-se uma proposta de metodologia de elaboração de Objeto de Aprendizagem com as seguintes etapas: Planejamento, Elaboração, Implementação e Avaliação. Como em outras metodologias apresentadas, essas etapas foram compartilhadas pelas equipes técnica e pedagógica. Segundo as autoras, as professoras das disciplinas responsabilizaram-se pela análise das necessidades de aprendizagem, por conhecerem os conteúdos e temas que estavam sendo abordados no ensino presencial. Foram propostas as elaborações do mapa conceitual e de roteiro, a partir dos quais foi iniciada a organização prévia do conteúdo evidenciado pelos mapas conceituais, e foram preparados pelo editor de texto (Word), sendo a seguir a encaminhados para a equipe de desenvolvimento.

Dessimone (2006) propôs uma metodologia de design de Objetos de Aprendizagem com base na engenharia de software educativo e no design de interação. As etapas para efetuar o Design de Objetos de Aprendizagem - DOA - são: Análise do conteúdo; Modelagem de Objetos de Aprendizagem; Design pedagógico; Design físico; Descrição dos

atributos de "metadados". A referida autora descreveu os resultados ou entregas para cada etapa prevista. Em relação aos resultados das atividades referentes à análise do conteúdo, por exemplo, têmse o seguinte resultado: a definição dos elementos constituintes que irão compor o modelo de Objetos de Aprendizagem pretenso; a identificação e localização dos elementos constituintes catalogados em repositórios disponibilizados na Internet; a análise de objetivos de aprendizagem e análise de atividades de aprendizagem; e a descrição de alguns atributos descritores de "metadados" dos elementos constituintes identificados na pesquisa documental. Enquanto, para a modelagem de Objetos de Aprendizagem têm-se os seguintes resultados: o conteúdo pretenso em elementos constituintes; as possíveis relações dos elementos constituintes; os elementos que irão compor o modelo de Objetos de Aprendizagem. Para realizar a decomposição do conteúdo pretenso, deve-se considerar que os elementos constituintes podem estar descritos em vários formatos, bem como apresentar características de diversos tipos de recursos de apoio didático. Dessimone (2006) recomenda a utilização dos guias pedagógicos e do professor da metodologia RIVED que serve para realização de um checklist para os OA desenvolvidos.

Braga (2014) propôs uma metodologia chamada INTERA - Inteligência em Tecnologias Educacionais e Recursos Acessíveis - e que foi inspirada nos processos de desenvolvimento de software e no modelo ADDIE para desenvolvimento de conteúdos instrucionais. Ela afirma também que a metodologia proposta deve ser considerada um arcabouço de processos para o desenvolvimento de qualquer tipo de conteúdo digital utilizado para a aprendizagem e que ela é aderente a qualquer tipo de Objeto de Aprendizagem, independentemente de sua granularidade, seu tamanho ou complexidade. A autora define ainda três (3) fases da metodologia INTERA: Inicial, Intermediária e de Transição e considera os papéis na metodologia INTERA: Analista, Conteudista, Gerente de projetos, Demandante, Designer de interface, Designer instrucional, Equipe de desenvolvimento e Equipe de Teste. Ela afirma, ainda, que para cada etapa deve existir um conjunto de atividades e práticas que variam conforme o tipo de objeto. As etapas da metodologia INTERA são: Contextualização, Requisitos, Arquitetura, Desenvolvimento, Testes e Qualidade, Disponibilização, Avaliação, Gestão de projetos e Ambiente e Padrões, sendo que cada etapa é dividida em três (3) elementos: i) Entrada; ii) Práticas e iii) Saída.

Os elementos de entrada são as informações e/ou artefatos necessários para o desenvolvimento das etapas. As práticas são técnicas - já consagradas e utilizadas na área de computação e/ou educação que podem ser usadas no desenvolvimento de um Objetos de Aprendizagem e variam conforme o seu tipo. Essas práticas não fazem parte da metodologia INTERA, no entanto a metodologia recomenda algumas delas. Outros elementos e técnicas também podem ser introduzidos na metodologia de acordo com a necessidade da equipe de trabalho. Os elementos de saída são informações ou artefatos gerados durante ou no final do desenvolvimento da etapa.

Rozenfeld (2008) propõe um modelo de referência baseado no Processo de Desenvolvimento de Produto - PDP. A proposta é dividida nas Macrofases, Pré-Desenvolvimento, Desenvolvimento e Pós-Desenvolvimento e estas são divididas, ainda, em fases como Planejamento Estratégico e Planejamento do Projeto (faz parte do Pré-Desenvolvimento), Projeto Informacional, Projeto Conceitual, Projeto Detalhado, Preparação da Produção, lançamento do Produto (Fazem parte do Desenvolvimento), Acompanhar Produto e Descontinuar (Fazem parte do Pós-Desenvolvimento). O modelo possui gates que são revisões realizadas ao final de cada fase que Rozenfeld (2006) define como atividade genérica. Ele considera o planejamento uma atividade genérica já que ele é atualizado no início de cada fase. Para cada fase, são realizadas entregas como, por exemplo, uma especificação em forma de documentos.

No projeto informacional, são entregues as especificações-meta, ou seja, as características ou requisitos do produto. A arquitetura do produto é a principal entrega realizada no projeto conceitual. 
A arquitetura é definida como a composição do produto em função dos seus elementos e a sua integração. Esses elementos são definidos como SSCs, Sistema, Subsistema e Componentes e têm suas especificações iniciais realizadas no projeto conceitual. No projeto detalhado, são desenvolvidos os SSCs de forma integrada.

\section{Proposta de um Processo para Desen- volvimento de Objeto de Aprendizagem}

O objetivo deste trabalho consiste em propor um Processo de Desenvolvimento de Objetos de Aprendizagem Interativo - PDOAI -, o qual foi elaborado a partir do estudo de várias metodologias, como vista na seção 2, tais como Kemczinski et al. (2012), Braga (2014), Lucena (2014), Dessimone (2006), Torres (2016) e no Processo de Desenvolvimento de Produto - PDP -, proposto por Rozenfeld (2006). Algumas observações são fundamentais sobre as definições de Objetos de Aprendizagem, neste trabalho. Primeiramente, a unidade de aprendizagem da Matriz de Design Instrucional - MDI - é um tópico quando relacionado com o programa da disciplina. Segundo, tópicos são constituídos de componentes ou elementos constituintes que podem ser definidos como Objetos de Aprendizagem atômicos, ou seja, não permite mais sua decomposição.

Em relação a Rozenfeld (2006), a metodologia utilizou a proposta de seus processos de desenvolvimento de produto - PDP - e dos seus aspectos gerenciais. No que tange aos aspectos gerenciais, a metodologia utiliza as atividades genéricas como os gates que são avaliações realizadas no final de cada fase e o planejamento que é atualizado em todo o início do processo de desenvolvimento de uma fase. Além dessas atividades, essa proposta sugere uma atividade de checklist por meio dos guias de orientação pedagógica e de orientação do professor da metodologia RIVED, apresentada por Dessimone (2006). Esse checklist apoia a atividade genérica de avaliação.

A metodologia proposta neste trabalho, também, utiliza a proposta de Braga (2014) e Rozenfeld (2006) com relação aos processos de entrada (artefatos), processo (práticas ou técnicas) e saída (artefatos) em cada fase, sendo que a metodologia, em relação a proposta de Kemczinski (2012), utiliza a Matriz de Design Instrucional. No estudo realizado na seção 2, todas as metodologias recomendam a utilização de ferramentas como mapa conceitual e storyboard. A Metodologia de Construção de Objetos de Aprendizagem Interativa - MCOAI proposto por Kemczinski (2012) sofreu aprimoramento por Lucena (2014) por meio da proposta de utilização de ferramentas de apoio para o preenchimento da MDI.

Assim, para cada fase, são gerados artefatos que são avaliados pelos gates. Esses artefatos são utilizados, portanto, como entradas para as fases seguintes do método proposto. Assim, as fases do Processo de Desenvolvimento de Objetos de Aprendizagem Interativo - PDOAI - aqui proposto são: Planejamento Estratégico; Planejamento; Projeto Informacional; Projeto Conceitual; Projeto Detalhado; e Disponibilização.

\section{Planejamento estratégico}

Essa primeira fase tem como objetivo analisar o portfólio da instituição e propor com base nas demandas os tipos de Objetos de Aprendizagem - OA - que serão desenvolvidos, como software, simulação, jogos, vídeo, textos e animações, por exemplo. Para os OA mais complexos, como software, serão necessárias uma estrutura computacional e uma equipe com um conhecimento técnico específico na área de desenvolvimento de software. Dessa forma, as ações sobre os tipos dos OA, prioridades, início e tempo de seus desenvolvimentos devem ser definidas no Planejamento estratégico. As ações sobre desenvolver os OA ou adquiri-los em outra instituição é uma decisão que deve ser discutida nessa fase, principalmente, para OA mais complexos. Ainda nessa fase inicial, devem ser definidos como eles serão gerenciados e quando serão começados.

\section{Planejamento}

Nessa fase, são realizadas as etapas de definição do escopo e detalhamento do escopo. O planejamento é considerado uma atividade genérica, ou seja, é atualizado a cada início de cada fase de um projeto. No escopo, são definidas a equipe, o conteúdo da disciplina por meio da sua ementa, a modalidade de ensino, a metodologia adotada, os objetivos, o tempo de início e o fim do projeto. No escopo detalhado, é desenvolvida a EAP - Estrutura Analítica de Projeto. Depois da construção da EAP, serão realizados o cronograma e o orçamento do projeto.

Uma observação importante, diz respeito à fase de projeto conceitual, quando o planejamento será atualizado e com ele a EAP é detalhada, pois a arquitetura do Objeto de Aprendizagem - OA - é disponibilizada. A arquitetura de um OA é definida como a estrutura de composição do OA com todos os seus componentes ou elementos constituintes e seus relacionamentos. Uma vez conhecidos os seus elementos constituintes, eles devem ser implementados na 
fase de projeto detalhado. As etapas para elaboração do planejamento são: definir o escopo do projeto; elaborar o detalhamento do escopo; elaborar o cronograma e elaborar o orçamento do projeto.

\section{Projeto informacional}

Para o desenvolvimento do projeto informacional, propõe-se a utilização da Matriz de Design Instrucional - MDI - (KEMCZINSKI, 2012), com apoio da estrutura de especificação de atividades propostas por Costa (2014). Primeiramente, devem-se dividir os objetivos em quatro fases: Introdução, Processo, Conclusão e Avaliação. Em seguida, identificam-se as atividades para as unidades de aprendizagem. Isto é, para cada objetivo e com a seleção de eventos sugeridos pela estrutura de especificação de aprendizagem deve-se buscar as atividades que façam o aluno interagir com o ambiente de aprendizagem. Assim, com o mapa conceitual e a MDI preenchida, pode-se dar uma visão geral sobre os OA a serem desenvolvidos. As etapas para elaboração do Projeto Informacional são: Elaborar o mapa conceitual das unidades de aprendizagem e Preencher as MDIs do projeto. As atividades devem ser transformadas em OA na fase seguinte projeto conceitual.

\section{Projeto conceitual}

Essa etapa tem como objetivo definir a arquitetura do Objeto de Aprendizagem. Assim, nesse momento serão definidos todos os OA com seus elementos constituintes e além deles, são identificados os tipos de OA e os roteiros de acesso pelos alunos. As informações contidas nas unidades de aprendizagem do Projeto informacional servirão de base para a elaboração dos roteiros de acesso a um OA. Primeiramente, ocorre a transformação de cada atividade em elemento constituinte do $\mathrm{OA}$ em desenvolvimento. A diferença básica entre a atividade e o elemento constituinte é a forma de definição. A atividade é uma ação, enquanto o elemento constituinte é a descrição de um conteúdo. Propõe-se, também, uma descrição desses elementos constituintes e um roteiro para cada elemento constituinte. Os roteiros definem a sequência dos assuntos a serem apresentados com os tipos dos elementos constituintes a serem utilizados.

No final, o Mapa Navegacional define as rotas de navegação de forma gráfica. Ele influencia a característica pedagógica de autonomia e deve possibilitar alternativas de navegação que não causem dúvidas no usuário na utilização do Objeto de Aprendizagem. As etapas para elaboração do Pro- jeto conceitual são: Atualizar o planejamento do projeto; Identificar os elementos constituintes dos OA por meio das atividades; Descrever os elementos constituintes dos OA; Identificar o roteiro para cada elemento constituinte; Desenvolver o mapa navegacional do OA.

\section{Projeto detalhado}

Na etapa de implementação, ocorre a participação dos profissionais técnicos (desenvolvedores), os quais acessarão as informações das etapas anteriores para criarem os Objetos de Aprendizagem. Essa fase tem uma ligação forte com o Planejamento estratégico, pois algumas decisões passam pelo seu processo de desenvolvimento, como, por exemplo, desenvolver um OA mais complexo. As escolhas das ferramentas serão discutidas nessa fase, já que no Projeto conceitual ocorreram algumas sugestões das ferramentas. Isto é realizado na atualização do planejamento que é realizado todo início de fase.

\section{Disponibilização}

Nesta fase, o Objeto de Aprendizagem é disponibilizado no Repositório de Objetos de Aprendizagem para sua posterior utilização.

\section{Atividades genéricas}

As atividades genéricas para essa proposta são: a atualização do planejamento, avaliação ou gates e os checklists com os guias pedagógicos e do professor da metodologia RIVED. A avaliação se dá nas diversas fases da metodologia proposta, porém as avaliações fundamentais são as realizadas antes da fase do projeto detalhado, já que o custo será alto se for identificado um erro nas fases anteriores apenas nesta fase.

Nas diversas fases, devem ser realizadas dois tipos de avaliações, a técnica e a pedagógica. $\mathrm{Na}$ avaliação técnica, o avaliador verifica as características técnicas do Objeto de Aprendizagem. Nessa etapa, o avaliador técnico pode aceitar ou recusar o Objeto de Aprendizagem. Se for aceito, o OA é enviado ao avaliador pedagógico, caso contrário, é rejeitado e o avaliador técnico notifica o gerente do projeto. Na etapa de avaliação pedagógica, o avaliador fará a avaliação do OA levando em consideração as características pedagógicas. Nessa etapa, o avaliador 
pedagógico pode aceitar ou recusar o Objeto de Aprendizagem. Assim, os professores conteudistas que participaram do Projeto informacional e conceitual deverão realizar uma verificação para identificar se as características pedagógicas estão agregadas ao objeto. Caso necessite mudanças, a documentação é alterada e o desenvolvedor é informado dos ajustes que precisam fazer. Já no caso de ser validada, o professor conteudista segue para a próxima fase da metodologia.

Após o término da etapa de avaliação, em caso de rejeição, retorna-se à etapa inicial de Análise e Projeto, para verificar a necessidade de mudança e, após isso, inicia-se a metodologia novamente. Caso o Objeto de Aprendizagem seja aceito, entra-se na fase de Disponibilização para uso no software de gerenciamento ou Repositório de Objetos de Aprendizagem.

\section{Desenvolvimento da Proposta}

Nesta seção, propõe-se o desenvolvimento da proposta em uma disciplina de Projeto Industrial com objetivo de avaliar e propor melhoria na metodologia em questão. Para tal, foi selecionada a unidade Pesquisa de mercado e, mais especificamente, o tópico Critérios Quantitativos de Previsão de Demanda da unidade de Pesquisa de mercado do programa da disciplina Projeto Industrial. Não foi objetivo, portanto, o desenvolvimento do programa de toda disciplina, mas apenas de um de seus tópicos.
Para validação da proposta, utilizam-se as fases e as ferramentas descritas na metodologia. O mapa conceitual geral da disciplina deve estar disponível para servir de base para o processo de desenvolvimento do Objeto de Aprendizagem. Uma outra observação importante é que o tema abordado é multidisciplinar e, por isso, os elementos constituintes do Objeto de Aprendizagem devem ser desenvolvidos de forma a facilitar sua reutilização.

\section{Planejamento}

Neste momento, o projeto foi liberado pelo planejamento estratégico para iniciar o projeto, definindose o escopo do projeto. Como pressupõe a metodologia, o mapa conceitual da disciplina com suas unidades e tópicos foi desenvolvido.

A disciplina, portanto, é constituída das seguintes unidades: Conceitos Gerais; Critérios Quantitativos de Análise Econômica de Projetos; Organização das Informações do Projeto. Financiamentos para o Projeto; Estudo de Mercado; Estudo da Localização do Projeto. Determinação da Escala; Tamanho do Projeto; Análise de Risco do Projeto.

A equipe é composta por três professores sendo um responsável mais diretamente pela aplicação da metodologia, já que lecionou a disciplina várias vezes, e os outros dois dando suporte quanto aos aspectos metodológicos e pedagógicos. A modalidade de ensino é híbrida, e a metodologia de ensino é centrada no aluno, usando problemas ou projetos

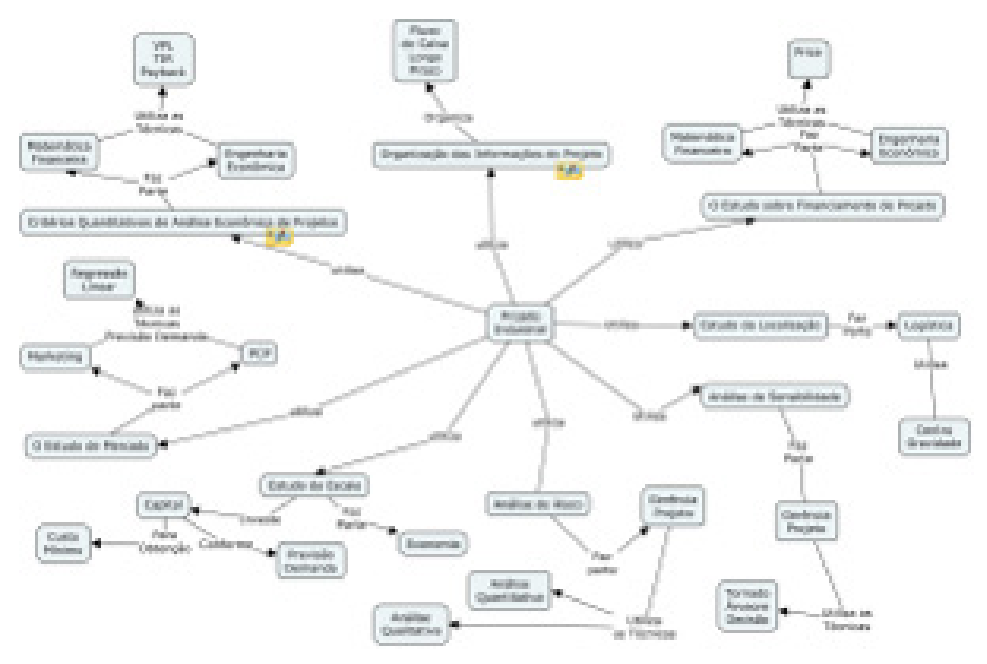

Figura 2: Mapa conceitual da disciplina. Fonte: Elaborado pelos autores 
e o conceito de aula invertida. O mapa conceitual é apresentado na figura 2.

O início do projeto para o tópico Previsão de Demanda, para fins de elaboração do cronograma, foi iniciado em 13.01.2017 e o encerramento no dia 31.01.2017. Os custos orçados são, principalmente, oriundos das horas trabalhadas pelos professores que estarão envolvidos no projeto informacional, conceitual e detalhado. A EAP é constituída, principalmente, das fases da metodologia e das suas entregas para a disciplina Projeto Industrial.

\section{Projeto informacional}

O projeto informacional foi dividido em duas etapas. A primeira etapa é a elaboração do mapa conceitual de cada unidade. A figura 3 mostra o mapa conceitual da unidade Estudo de Mercado que será a unidade estudada neste trabalho. Os elementos do mapa conceitual apoiam a iden-

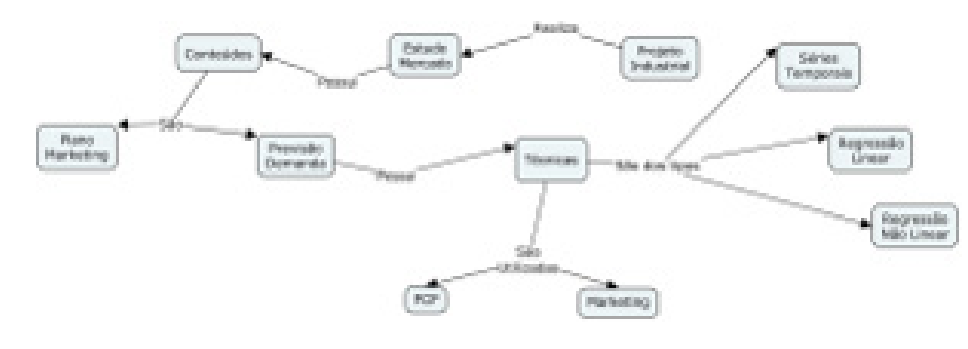

Figura 3: Mapa conceitual da unidade estudada. Fonte: Elaborado pelos autores

tificação dos tópicos que são candidatos a um Objeto de Aprendizagem. Esse OA faz parte de um OA maior chamado de Estudo de Mercado. No mapa, podem ser identificados dois tópicos que devem se tornar OA, são eles Previsão de Demanda e Plano de Marketing, porém apenas o tópico Previsão de Demandas foi selecionado para este estudo, o qual possui técnicas que são utilizadas em outras disciplinas como Planejamento e Controle da Produção - PCP - e Marketing. Os elementos do mapa conceitual apoiam nos processos de especificação dos objetivos e das atividades da Matriz de Design Instrucional.

A segunda etapa está relacionada ao preenchimento da Matriz de Design Instrucional com a especificação dos objetivos e das atividades, e está apresen- tada nos quadros 1 e 2, a seguir. Para esses quadros, serão mostrados somente uma atividade para cada objetivo dentro de suas fases, embora outras atividades tenham sido identificadas.

\section{Projeto Conceitual}

Nessa fase, são identificados os elementos constituintes do Objeto de Aprendizagem Previsão de Demanda, as interações com os alunos e o roteiro para elaboração do storyboard. O roteiro é identificado a partir do mapa conceitual, da Matriz de Design Instrucional preenchida, e, principalmente, dos Objetos de Aprendizagens e elementos constituintes, apresentados a seguir nos quadros 3, 4 e 5 .

\begin{tabular}{ll} 
Fase & Objetivos \\
Introduçao & 1 Definir conceitos e aplicações de previsão de demandas \\
\hline Processos & 2 Ilustrar as técnicas de previsão de demandas \\
\hline conclusão & 3 Formular e aplicar as técnicas de previsão de demandas em um projeto industrial \\
\hline avaliação & 4 Avaliar aprendizagem com problemas e questões sobre previsão de demandas \\
\hline
\end{tabular}

Quadro 1: Especificação dos objetivos do OA - Critérios quantitativos de previsão de demanda Fonte: Elaborado pelos autores 


\begin{tabular}{lll} 
Fase & Objetivos & Atividades \\
Introduçao & Objetivo 1 & $\begin{array}{l}\text { Apresentar os conceitos e aplicações das técnicas de previsão } \\
\text { de demandas }\end{array}$ \\
\hline Processos & Objetivo 2 & Explicar os cálculos com as técnicas de previsão de demandas \\
\hline conclusão & Objetivo 3 & $\begin{array}{l}\text { Elaborar aplicações de previsão de demandas para Projetos } \\
\text { Industrial }\end{array}$ \\
\hline avaliação & Objetivo 4 & Elaborar questões sobre previsão de demandas \\
\hline
\end{tabular}

Quadro 2: Especificação das atividades do OA - Critérios quantitativos de previsão de demanda. Fonte: Elaborado pelos autores

Devido a apresentação ter sido somente para alguns elementos constituintes do Objeto de Aprendizagem Previsão de Demandas, este estudo não apresentou o mapa navegacional. Neste trabalho, o mapa foi idealizado com os elementos constitu- intes de cada fase sendo utilizado de forma paralela. Por exemplo, para fase Introdução, três elementos poderiam ser acessados paralelamente, e, em seguida, uma avaliação era realizada. Isto foi

\section{Atividades}

\section{Critérios quantitativos de previsão de demandas}

Apresentar os conceitos e aplicações das técnicas de previsão de demandas

As técnicas de previsão de demanda, conceitos e suas aplicações

Explicar os cálculos com as técnicas de previsão de demandas

Fórmulas e cálculos com as técnicas de previsão de demandas

Elaborar aplicações de previsão de demandas para projetos industrial

As técnicas de previsão de demandas, exemplos e soluções para projetos industrial

Elaborar questões sobre previsão de demandas

Questões sobre previsão de demandas

avaliação

Elaborar questões sobre previsão de demandas

Quadro 3: Atividades e Objetos de aprendizagens. Fonte: Elaborado pelos autores. 


\section{$\begin{array}{ll}\text { Processos } & \begin{array}{l}\text { Critérios quantitativos } \\ \text { de previsão de demandas }\end{array} \text { Descrição Elementos Constituintes }\end{array}$}

\begin{tabular}{|c|c|c|}
\hline Introdução & $\begin{array}{l}\text { As técnicas de previsão de deman- } \\
\text { da, conceitos e suas aplicações }\end{array}$ & $\begin{array}{l}\text { Este elemento tem como objetivo apresentar as } \\
\text { técnicas de previsão de demandas e suas aplicações } \\
\text { em diversas áreas como PCP, Marketing e Projeto } \\
\text { Industrial, por exemplo. Assim, as aplicações po- } \\
\text { dem ser vistas como de curto, médio e longo prazo. } \\
\text { Podem ser utilizados um vídeo e um texto para este } \\
\text { elemento. }\end{array}$ \\
\hline Processo & $\begin{array}{l}\text { Fórmulas e cálculos com as técni- } \\
\text { cas de previsão de demandas }\end{array}$ & $\begin{array}{l}\text { Este elemento apresenta fórmulas e cálculos com } \\
\text { exemplos de aplicações para previsão de demandas } \\
\text { em geral. Podem ser utilizados vários vídeos e tex- } \\
\text { tos de técnicas de previsão de demandas para esse } \\
\text { elemento. Existe, pelo menos, um vídeo e um texto } \\
\text { para aplicações em Projeto Industrial. }\end{array}$ \\
\hline Conclusão & $\begin{array}{l}\text { As técnicas de previsão de de- } \\
\text { mandas, exemplos e soluções para } \\
\text { Projeto Industrial }\end{array}$ & $\begin{array}{l}\text { Este elemento mostra exemplos e resoluções para } \\
\text { aplicações em Projeto Industrial. Podem ser utiliza- } \\
\text { dos vídeo e texto para esse elemento. }\end{array}$ \\
\hline avaliação & $\begin{array}{l}\text { Questões sobre previsão de deman- } \\
\text { das }\end{array}$ & $\begin{array}{l}\text { Este elemento tem como objetivo propor questões } \\
\text { sobre os conteúdos de previsão de demandas dos } \\
\text { diversos elementos apresentados acima. Pode ser } \\
\text { desenvolvido um software, como um jogo, para este } \\
\text { elemento. Este elemento é utilizado em conjunto } \\
\text { com o elemento proposto abaixo. }\end{array}$ \\
\hline
\end{tabular}

Quadro 4: Descrição dos elementos constituintes. Fonte: Elaborado pelos autores. 
As técnicas de previsão de demanda, conceitos e suas aplicações
Em primeiro lugar é apresentado o conceito e objetivo das técnicas de previsão de demandas. Em seguida, são identificados os tipos de técnicas e suas características e suas aplicações em diversas áreas como PCP, Marketing e Projeto Industrial, por exemplo. Por último, são apresentadas aplicações para os diversos tipos de técnicas.
Utilizar um texto único para o elemento constituinte $\mathrm{e}$ um vídeo com os conceitos, objetivos e aplicações sobre as técnicas de previsão de demandas. E um vídeo para cada tipo de técnica. O elemento constituinte é dividido em outros elementos constituintes. Assim, como existem vários outros elementos constituintes, utilizar um software para gerenciar o roteiro de acesso a esses elementos constituintes pelo aprendiz.
Inicialmente, são mostradas as técnicas e conforme a seleção pelo aprendiz, são apresentadas as fórmulas e cálculos para técnica de previsão de demandas selecionada.
Idem

Fórmulas e cálculos com as técnicas de previsão de demandas
Quadro 5: Roteiro do OA - Critérios quantitativos de previsão de demanda. Fonte: Elaborado pelos autores. realizado para as outras fases como Processo, Conclusão e Avaliação.

\section{Projeto detalhado}

Nessa fase, foi implementado um Objeto de Aprendizagem utilizando o software de autoria eXeLearning. Essa ferramenta foi selecionada em função de sua facilidade de aprendizagem e usabilidade de sua interface. Trata-se de uma ferramenta do tipo What You See Is What You Get - o que você ver é o que você tem.

Nessa implementação, o maior nível do Objeto de Aprendizagem é a disciplina Projeto Industrial. Esse objeto, então, foi dividido em nove outros objetos de aprendizagens chamados de unidades. A figura 4, a seguir, mostra o menu do OA da disciplina Projeto Industrial.

Para cada unidade, foram definidos um conjunto de outros objetos chamados de tópicos. E, para cada tópico, foram definidos seus Objetos de Aprendiza- gens chamados de tarefas. Esses são os objetos de nível mais baixo, ou seja, são Objetos de Aprendizagens que definem os seus elementos constituintes, os quais não podem mais ser subdivididos. A figura 4 mostra o menu do OA da disciplina Projeto Industrial e a figura 5 mostra os nove Objetos de Aprendizagens para Critérios Quantitativos de Previsão de Demandas. Os quadros da seção anterior mostraram somente quatro Objetos de Aprendizagens, enquanto esse OA Critérios Quantitativos de Previsão de Demandas apresenta um para cada processo.

A figura 6 mostra os elementos constituintes para o OA As Técnicas de Previsão Este objeto pertence ao OA Critérios Quantitativos de Previsão de Demandas, o qual pertence ao OA Estudo de Mercado, unidade 5. Por exemplo, ao clicar no OA Técnicas de Previsão de Demanda, Conceitos e suas Aplicações uma nova interface mostra os elementos constituintes deste OA que são um texto, um vídeo e uma questão para reflexão. Esses elementos constituintes foram apresentados nos quadros 4 e 5 da 


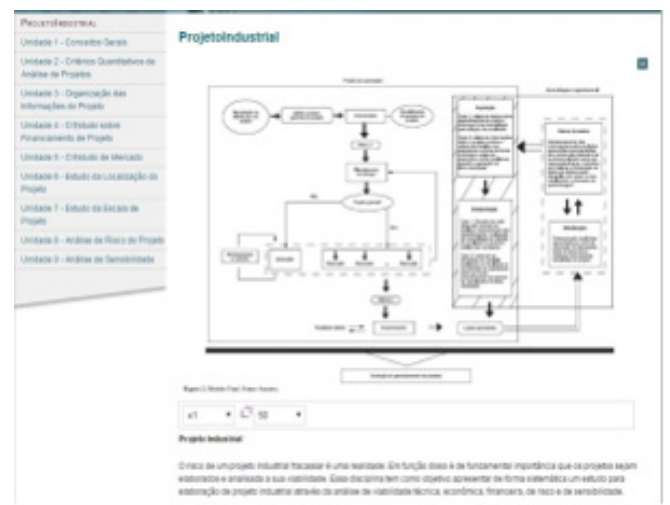

Figura 4: Menu do OA da disciplina projeto industrial. Fonte: Elaborado pelos autores

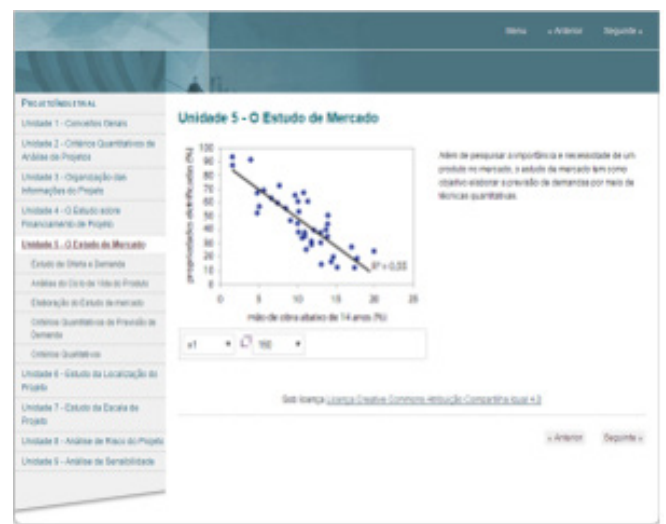

Figura 5: OA das técnicas de Previsão de demandas. Fonte: Elaborado pelos autores

seção anterior.

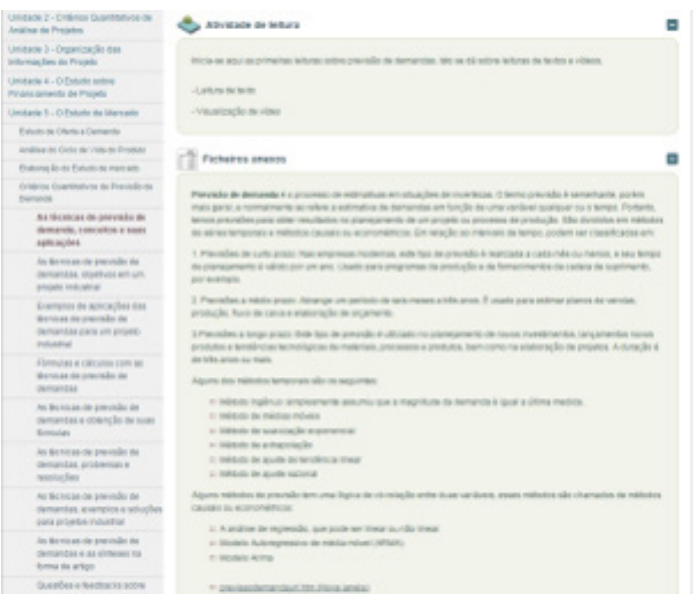

\section{Considerações Finais}

O desenvolvimento de Objetos de Aprendizagem

Figura 6: OA das técnicas de previsão de demandas Fonte: Elaborado pelos autores 
apropriados e atraentes aos alunos tende a favorecer a utilização desses recursos e, portanto, ampliar as possibilidades de incremento das ações pedagógicas com vistas a promover uma aprendizagem significativa.

Nesse sentido, este estudo analisou metodologias de elaboração de Objetos de Aprendizagem e propôs um Processo de Desenvolvimento de OA In-

terativo - PDOAI - como sendo um conjunto de atividades capaz de transformar informações tecnológicas e pedagógicas em $\mathrm{OA}$, conforme a estratégia da instituição, atendendo às necessidades da sua estrutura de desenvolvimento.

Para o desenvolvimento desse processo foram estabelecidas fases, a saber, de Planejamento Estratégico, Planejamento, Projeto Informacional, Projeto Conceitual, Projeto Detalhado e Disponibilização. O desenvolvimento realizado para validação da proposta evidenciou a adequação dessa metodologia, na medida em que facilitou o desenvolvimento de Objetos de Aprendizagem adequados às necessidades institucionais.

\section{Referências}

ABARCA, Reyna Melara (2014) et al. Wikification of Learning Objects Using Metadata as an Alternative Context for Disambiguation. Computación y Sistemas, Vol. 18, No. 4, 2014, pp. $755-765$.

BELLOCH, Consuelo (2017). Diseño Instrucional. Acessado em 04.01.2017.

BRAGA, Juliana (2014) et al. Objetos de Aprendizagem. Volume 1 - Introdução e Fundamentos. Santo André, SP. Editora da UFABC. Coleção INTERA.

(2014) et al. Objetos de Aprendizagem Volume 2 - Metodologia de Desenvolvimento. Santo André, SP. Editora da UFABC. Coleção INTERA.

COSTA, Ismael Antiqueira et al. (2014). Matriz de Design Instrucional da Metodologia para a Construção de Objetos de Aprendizagem Interativos. Nuevas Ideas en Informática Educativa TISE, 2014 .

DESSIMONE, Teresa Cristina Gurgel (2006). Design de objetos de aprendizagem com bases na engenharia de software educativo e no design de interação. Dissertação apresentada ao Programa de Pós-Graduação em Ciências da Computação da Universidade Estadual do Ceará. Dezembro de 2006.

KEMCZINSKI, Avanilde et al. (2012). Metodologia para Construção de Objetos de Aprendizagem Interativos. Anais do $23^{\circ}$ Simpósio Brasileiro de Informática na Educação (SBIE 2012), ISSN 23166533 Rio de Janeiro, 26-30 de Novembro de 2012. 
LUCENA, Sergio Vinícius (2014). Modelagem de requisitos baseada em cenários para o Storyboard da Metodologia para Construção de Objetos de Aprendizagem Interativos. Nuevas Ideas en Informática Educativa TISE 2014.

OKADA, Alexandra (2016). Mapas do Conhecimento com Recursos Educacionais Abertos Aplicados á Coaprendizagem Baseada em Coinvestigação. Coleção Agrinho. Acessado na Internet em 05.10.2016.

ROZENFELD, Henrique et al. (2006). Gestão do desenvolvimento de produtos: uma referência para melhoria de processos. São Paulo. Editora Saraiva.

TORRES, Patrícia Lupion et al. (2016). O uso de objetos aprendizagem em curso de extensão a distância. Acessado na internet em 22.11.2016 